\title{
Agricultural Utilization and Year-Round Rearing Techniques of Bumblebees in Korea
}

\author{
Hyung Joo Yoon*, Kyeong Yong Lee, Mi Ae Kim and In Gyun Park \\ Applied Entomology Division, Department of Agricultural Biology, National Academy of Agricultural Science, Suwon 441- \\ 100, Korea
}

(Received 17 April 2011; Accepted 19 May 2011)

\begin{abstract}
Commercially managed bees are available for pollination services and are used in large commercial fields, small gardens, or enclosures such as greenhouses and screen houses. This paper describes the current status and agricultural utilization of commercially managed bumblebees as well as bumblebee rearing techniques in Korea. We surveyed the use rate and number of bumblebees for the pollination of $\mathbf{1 0}$ major horticultural crops and fruit trees in Korea; in 2009, the use rates were approximately $7.9 \%$ and $2.8 \%$, respectively. The use number of bumblebees as pollinators was more than 64,345 colonies, which included 51,400 colonies for 10 major horticultural crops and 12,945 colonies for 10 major fruit trees in 2009. The value of bumblebees as pollinators in 2009 in Korea was estimated at more than $5,100,000,000$ won. We also describe feeding, rearing room conditions, colony initiation, mating and diapause breaks to establish year-round mass rearing techniques of the bumblebee Bombus ignitus.
\end{abstract}

Key words: Insect pollinator, Bumblebee, Commercial rearing, Economic value

\section{Introduction}

Arguably, the most important activity of bees is their pollination of natural vegetation and agricultural plants including fruits, vegetables, seed plants, edible oil crops, garden flowers, fiber crops such as flax and cotton, and

\footnotetext{
*To whom the correspondence addressed Department of Agricultural Biology, National Academy of Agricultural Science, RDA, Suwon 441-100, Korea. Tel \& Fax: +82-31-290-8567; E-mail: yoonhj1023@korea.kr
}

major forage crops. Bees are diverse and abundant, with 16,325 identified species throughout the world (Michener, 2000). However, the true number of bee species is actually unknown because not all have been named and some have yet to be identified or discovered. Insect pollination is both an ecosystem service and a production practice used extensively by farmers all over the world for crop production. We rely on bees to pollinate 87 (or $70 \%$ ) of the 124 most valuable crops used directly for human consumption (Klein et al., 2007). In Europe, the production of $84 \%$ of crop species depends directly on insect pollinators, especially bees (Williams, 1994). Worldwide, bees pollinate more than 400 crop species and, in the United States, more than 130 crop species (James and PittsSinger, 2008).

Pollination is an ecosystem service in that wild pollinators, in particular wild bees, contribute significantly to the pollination of a large array of crops (Morandin and Winston, 2005; Greenleaf and Kremen, 2006; Winfree et al., 2007). Commercially managed bees are also available for pollination services and are used in large commercial fields, small gardens, or enclosures such as greenhouses and screen houses. Although the general public gives honeybees much of the credit for pollination, managed bumblebees and solitary bees also have a great impact on certain commodities (Free, 1993; Dag and Kammer, 2001). Thus, the economic benefit of insect pollination is clear for farmers, and the market for colony rental of honeybees is now well developed and organized in the United States (Sumner and Boriss, 2006) and Europe (Carreck and Williams, 1998), as well as for bumblebees all over the world (Velthuis and van Doorn, 2006). For the 100 crops used for human food worldwide, the global economic value of pollination totaled $€ 153$ billion in 2005, or approximately $9.5 \%$ of the value of the world agricultural production used for human food (Gallai et al., 2009).

Here, we discuss the current status and agricultural uti- 
lization of commercially managed bumblebees used as pollinators in Korea. We also describe year-round techniques for rearing the Korean native bumblebee, Bombus ignitus.

\section{Agricultural utilization of bumblebees in Korea}

The introduction of bumblebees into greenhouses for pollination has become widespread in recent years, and demand increases annually. Bumblebees provide farmers the opportunity to decrease their pollination labor costs and promise a good crop yield, both in quantity and in quality (Velthuis and van Doorn, 2006). Bumblebees are more effective than honeybees in cloudy weather and in small areas, such as greenhouses. Bumblebees also tend to devote themselves mainly to the crops within the greenhouse, whereas honeybees are apt to escape en masse to the outside. Bumblebees are particularly effective at pollinating Solanaceae species, including the tomato and eggplant.

Since 1987, bumblebees have been available commercially in portable boxes for crop pollination (Mitsuhata, 2000). Today, there are over 30 producers worldwide, but most of the market share is captured by 3 companies: Biobest (Belgium), Koppert Biological Systems (Netherlands) and BBB (Bunting Brinkman Bees, Netherlands). The larger companies have rearing facilities not only in their homeland but also in other countries and on other continents, usually under their own name (Velthuis and van Doorn, 2006). Currently, five species of bumblebees are reared commercially: B. terrestris, B. t. canariensis, $B$. lucorum, B. ignitus, B. occidentalis and B. impatiens. The number of bumblebees sold in 2004 was estimated to be approximately one million: approximately 930,000 colonies of the Eurasian B. terrestris, approximately 55,000 colonies of the North American B. impatiens, and a few thousand colonies of the Eurasian B. lucorum, East Asian B. ignitus, and North American B. occidentalis (Velthuis and van Doorn, 2006).

In 1994, 2,300 B. terrestris colonies were first introduced into Korea. We transferred more than 10 patents and 20 bumblebee rearing techniques to farmers for commercial rearing of bumblebees from 2004. Since then, many more producers have started rearing bumblebees commercially. There are over 10 producers in Korea today (e.g., Sesil Corporation, Green-Agrotec Company, Daesan Company, Yaecheon Entomology Institute, Nuribul Company, Boseong-Sujeongbul Company, Jayeon-Sujeongbul Company, Dure-Sujeongbul Company et al.). The total number of bumblebee colonies produced in 2009 was over 650,000 , of which 45,500 colonies $(70 \%)$ were produced by Korean bumblebee companies and 19,500 colonies were imported from foreign sources (Yoon, H.J., personal communication, 2010). In 1994, the value of a

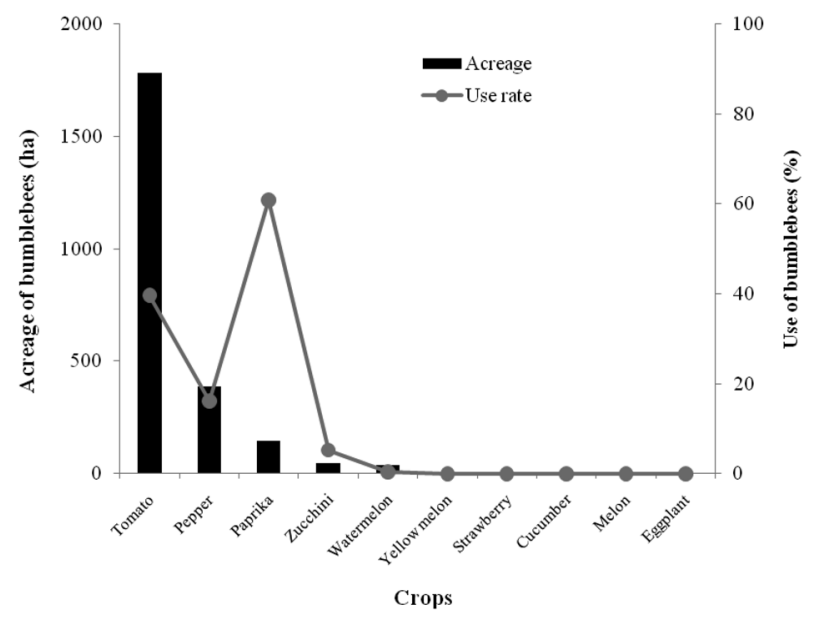

Fig. 1. Acreage and use rate of bumblebees used for the pollination of 10 major horticultural corps in greenhouses, 2009.

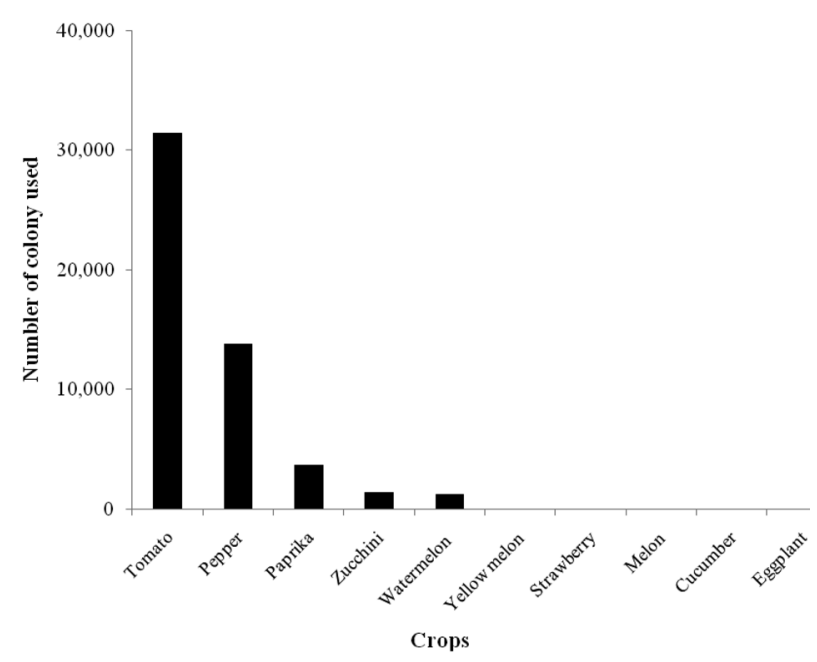

Fig. 2. Number of bumblebee colonies used for the pollination of 10 major horticultural corps in greenhouses, 2009.

bumblebee colony was 200,000 won. Now, 15 years later, the value is 75,000 won, which is more than $60 \%$ cheaper than in 1994.

In Korea, the rate of the use of bumblebees as pollinators for 10 major horticultural crops averaged $7.9 \%$, which was calculated including paprika $(60.9 \%)$, tomato (39.7\%), pepper (16.2\%), zucchini $(5.2 \%)$ and watermelon $(0.4 \%)$. Bumblebees were not used as pollinators for yellow melon, strawberry, cucumber, melon or eggplant (Fig. 1). The number of bumblebee colonies used for 10 horticultural crops in greenhouses was estimated to be 51,400 , which included 31,406 for tomatoes, 13,780 for peppers, 3,632 for paprika, 1,352 for zucchini, and 1,230 for watermelon. The number of bumblebee colonies used was estimated to be more than 51,400 (Fig. 2). We also investigated the role of bumblebees used for 10 major 


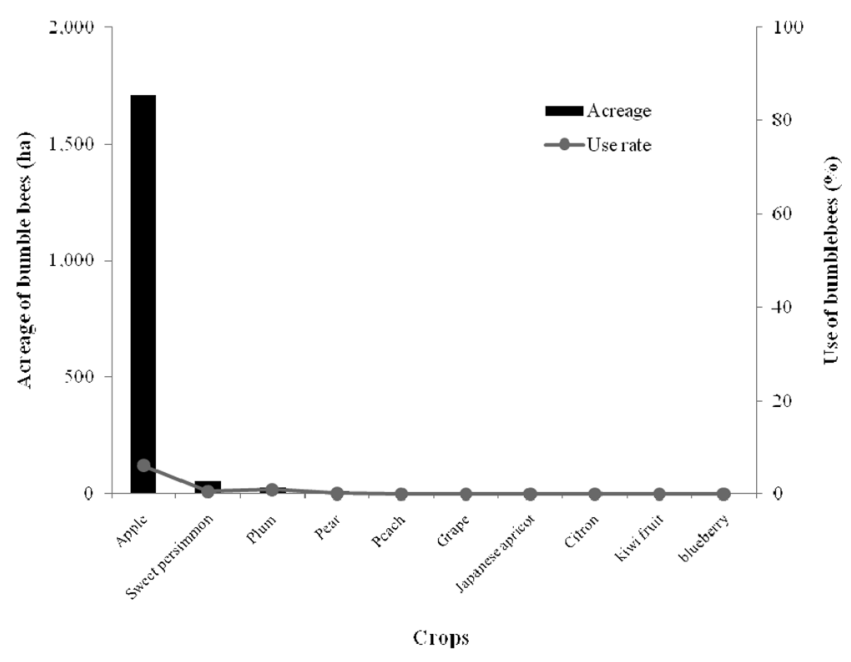

Fig. 3. Acreage and use rate of bumblebees used for the pollination of 10 major fruit trees in 2009.

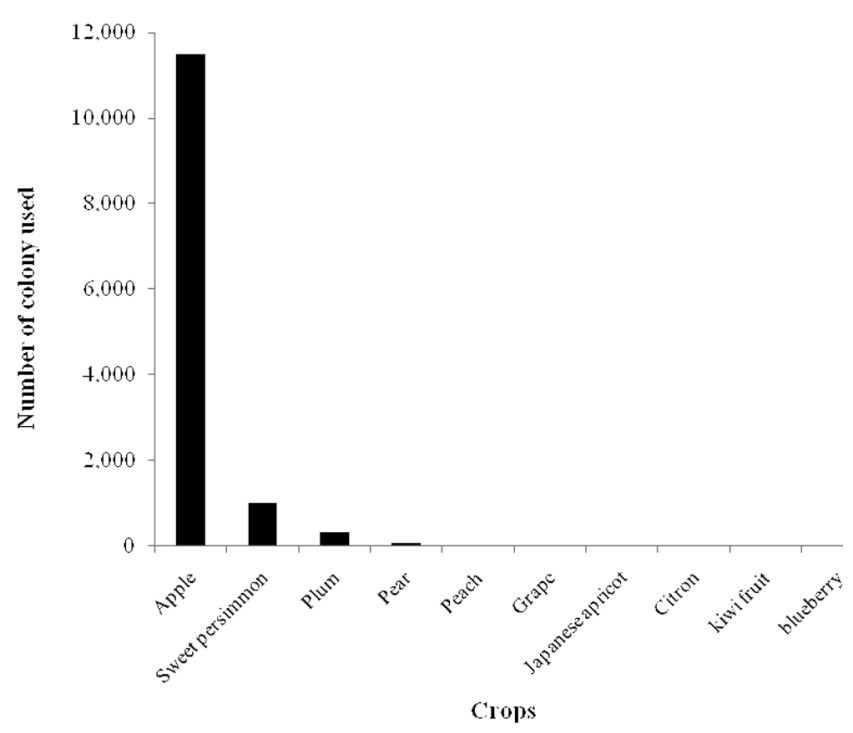

Fig. 4. Number of bumblebee colonies used for the pollination of 10 major fruit trees in 2009.

fruit trees. The rate of use of bumblebees for 10 major fruit trees averaged $2.8 \%$, which was calculated including apple $(6.1 \%)$, plum $(0.9 \%)$, sweet persimmon $(0.5 \%)$, and pear $(0.1 \%)$. There was no use of bumblebees as pollinators for peach, grape, Japanese apricot, citron, kiwi fruit or blueberry (Fig. 3). The number of colonies used for the 10 major fruit trees was estimated to be 12,945 , which included 11,501 for apple, 1,018 for sweet persion, 339 for plum, and 87 for pear (Fig. 4). The number of bumblebee colonies used for pollination of the 10 major horticultural crops and fruit trees was estimated to be more than 64,345 .

\section{Artificial rearing of the bumblebee $B$. ignitus}

The large bumblebee, $B$. terrestris, which is indigenous to Europe, has been artificially introduced in several parts of the world. Within its distribution area, B. terrestris is represented by approximately 10 subspecies that differ in their coloration (Kruger, 1958). Colonies of most of the subspecies of $B$. terrestris have been used outside of their natural distribution area. Colonies of $B$. terrestris have been imported into many countries, including Korea, Japan, China, Taiwan, Mexico, Chile, Argentina, Uruguay, South Africa, Morocco, and Tunisia (Dafni, 1998). There has been some anxiety associated with the introduction of $B$. terrestris into greenhouses because it is highly invasive, could potentially escape from greenhouses, and could have negative effects on native bumblebees through competition (Ono and Wada, 1996; Velthuis and van Doorn, 2006) or genetic contamination by hybridization (Velthuis and van Doorn, 2006). The competitive displacement of native pollinators and the invasion of native vegetation by $B$. terrestris have already been recorded in Tasmania (Semmens et al., 1993). In Israel, the numbers of honeybees and solitary bees have declined with the range expansion of $B$. terrestris (Dafni and Shimida, 1996). B. terrestris has also colonized Japan, where it escaped from greenhouses in 1996 after its introduction in 1991 (Washitani, 1998). For this reason, the governments of Canada and the USA prohibit the introduction of foreign bumblebee species, and at present, a native bumblebee, $B$. impatiens, is used for commercial pollination in North America (Velthuis and van Doorn, 2006). In Korea, B. terrestris was first introduced in 1994, and in early May 2002 to 2009, overwintering B. terrestris queens were caught in several regions (Yoon et al., 2009). In our hybridization studies of $B$. ignitus and $B$. terrestris, interspecific hybridization occurred between $B$. ignitus and $B$. terrestris, which suggests that the hybridization will have a negative impact on competition and increase genetic pollution among native bumblebees (Yoon et al., 2009).

We are studying the artificial, year-round mass rearing of $B$. ignitus because this species showed the best results both in artificial reproduction and in pollinating ability out of seven native Korean bumblebees (Yoon et al., 1999, 2002, 2003, 2004a). We describe the year-round mass rearing of $B$. ignitus for the pollination of greenhouse plants.

\section{Feeding}

In artificial mass-rearing of bumblebees, all previous investigators have used pollen and honey obtained from honeybee hives (Griffin et al., 1991; Tasei and Aupinel, 1994; Ono et al., 1994b; Hannan et al., 1998), though the 
supplying method varied somewhat among various experiments. We investigated the effect of different concentrations of sugar solution and the addition of antiseptic to the solution on oviposition and colony development of $B$. ignitus. The rates of oviposition, colony foundation and progeny-queen production of $B$. ignitus were $1.2-3.0$ fold higher in those receiving a $40 \%$ sugar solution than in those receiving a $50 \%$ sugar solution. The rates of oviposition, colony foundation and progeny-queen production were 1.1-2.6 fold higher in those receiving a $40 \%$ sugar solution combined with $0.3 \%$ sorbic acid as an antiseptic than in those receiving only a $40 \%$ sugar solution. Further, the death rate within one month was 1.7 fold lower in those receiving a $40 \%$ sugar solution combined with $0.3 \%$ sorbic acid than in those receiving a $40 \%$ sugar solution alone. Therefore, the $40 \%$ sugar solution was more effective than the 50\% sugar solution, and the $40 \%$ sugar solution combined with antiseptic was the most effective for colony development and mass rearing of bumblebees (Yoon et al., 2005b). For the types of pollen, oviposition and colony development of $B$. ignitus were not affected by fresh-freezing or dry-freezing pollen. This result indicates that dried pollen, which is dried in the shade for 5-6 days, is a viable commercial pollen for bumblebee reproduction (Yoon et al., 2005a). Therefore, a $40 \%$ sugar solution with $0.3 \%$ sorbic acid and fresh, blended pollen were used as food for B. ignitus (Yoon et al., 2002, 2005b, 2005a).

For bumblebees, pollen is considered to be a non-energetic resource that primarily provides proteins for female egg production and/or larval growth (Plowright and Pendrel, 1977). Proteins are required for oogenesis in B. terrestris workers and influence adult size (Duchâteau and Velthuis, 1989; Sutcliffe and Plowright, 1988). Ribeiro et al. (1996) found that drying pollen, which is assumed to modify some amino acids, lipids, or vitamins of the pollen, affected the reproductive capacities of $B$. terrestris queens. However, the degree of impairment depends mainly on the drying methods (Groot, 1953). For this reason, it is recommended that the temperature during the drying process should not exceed $45^{\circ} \mathrm{C}$ and that the moisture should be removed gradually (Chambers, 1990). We found that the success in rearing bumblebees is better with pollen containing a high protein content (e.g., from Brassica and Prunus) than with pollen from other plant species (e.g., Helianthus and Taraxacum). However, lower rearing success could be caused by a deficiency in other components, such as an essential amino acid or a vitamin, instead of the low protein content that characterizes some insect-pollinated and many wind-pollinated plants (Stanley and Linskens, 1974; Schmidt et al., 1987; Day et al., 1990; Regali and Rasmont, 1985; Roulston and Cane,
2000; Aupinel et al., 2001; Génissel et al., 2002).

\section{Conditions in the rearing room}

The optimum temperature and humidity for the indoorrearing of $B$. ignitus were investigated. The experimental temperature and humidity conditions tested were $23^{\circ} \mathrm{C}$, $27^{\circ} \mathrm{C}$ and $30^{\circ} \mathrm{C}$ at a constant humidity of $65 \%$ R.H., and $50 \%, 65 \%$ and $80 \%$ R.H. at a constant temperature of $27^{\circ} \mathrm{C}$. The conditions $27^{\circ} \mathrm{C}$ and $65 \%$ R.H. were determined to be the most favorable environmental conditions for colony development of $B$. ignitus in indoor rearing (Yoon et al., 2002). The Japanese B. ignitus and B. hypocrita hypocrita were reared at $26^{\circ} \mathrm{C}-28^{\circ} \mathrm{C}$ (Ono, 1999; Hannan et al., 1988), and the western bumblebee, B. terrestris, was reared at $29^{\circ} \mathrm{C}-30^{\circ} \mathrm{C}$ (Beekman, 2000; Duchateau and Velthuis, 1988).

Photoperiodic cues change the life history of organisms. The effect of photoperiodic regimes on the oviposition and colony development of $B$. ignitus queens was examined with $0 \mathrm{~L}$ (continuous dark), $8 \mathrm{~L}$ (light for $8 \mathrm{hrs}$ per day), and $16 \mathrm{~L}$ (light for $16 \mathrm{hrs}$ per day) under $27^{\circ} \mathrm{C}$ and $65 \%$ R.H. The light conditions ( $8 \mathrm{~L}$ and $16 \mathrm{~L}$ ) were more suitable than the dark condition $(0 \mathrm{~L})$ for oviposition and colony development for $B$. ignitus in indoor rearing conditions (Yoon and Kim, 2003). Diapause in insects is usually affected by the photoperiod (Danilevskii, 1965). Because oviposition in the bumblebee is also related to adult diapause, the possibility must be allowed that the photoperiod affects the oviposition of the queen and further development of colony. The bumblebee is generally reared in dark conditions (Plowright and Jay, 1966; Heemert et al., 1990; Asada and Ono, 2000). However, Tasei and Aupinel (1994) tested different photoperiodic regimens and found that, for colony initiation, a daily period of eight hours produced the best results.

\section{Colony initiation}

We investigated whether or not helpers, such as worker bees, bee-cocoons and egg-cups, affect oviposition and colony foundation by the queen bumblebee in $B$. ignitus to stimulate colony initiation. Among the helpers tested, callow workers of $B$. ignitus and B. terrestris showed the most substantial effects on the rates of oviposition: $92 \%$ and $88 \%$, respectively. A narcotized old worker, aged 10 days after emergence, showed similar effects to a callow worker on colony development. For the number of workers recruited to a foundation queen, two workers showed a better effect than one worker on colony development (Yoon and Kim, 2002). Several starting methods such as adding a male $B$. terrestris pupa, young honeybees and bumblebee workers, a combination of $B$. terrestris workers and single pupa are used to stimulate colony ini- 
tiation. Ptacek $(1985,1991)$ and Eijnde et al. (1991) used honeybee workers instead of bumblebee workers and obtained good results in B. terrestris with this method. Ono et al. (1994) used workers of B. terrestris to stimulate the queens of the closely related B. hypocrita. Gretenkord and Drescher (1997) compared several stimulating methods and found that a combination of $B$. terrestris workers and larvae was the most successful method for stimulating $B$. terrestris queens.

We also investigated whether the developmental characteristics of B. ignitus foundation queens would be affected by the first oviposition day. The results revealed that a queen with an early first oviposition day could make a stronger colony and could make the colony formation period shorter; therefore, the timing of the first oviposition day of foundation queens was shown to be a criterion for the selection of supercolonies when B. ignitus is raised indoors. In this study, the colony development of queens that laid eggs within 20 days was better than those of queens that oviposited after 20 days. Given these results, discarding queens that oviposit after 20-40 days seems to be economic in year-round mass rearing of bumblebees (Yoon et al., 2004a). Duchateau (1991) reported that failure of the foundress queen in first-brood rearing seemed to influence further colony development. The queens of artificially hibernated $B$. terrestris that oviposited after 40 days in indoor-rearing are regarded as non-diapausing (Beekman et al., 1996).

\section{Mating}

We investigated the following mating conditions to improve the mating rate of $B$. ignitus: mating time, photoperiod, illumination, and temperature during mating periods; care temperature of the queen before mating; mating period; and the number of queens per mating cage. Mating of a five-day-old virgin queen and a ten-day-old male usually lasts, on average, 23 minutes (range 10$38 \mathrm{~min}$ ) (Yoon et al., 1999). Among photoperiodic regimes of $12 \mathrm{~L}$ (light for $12 \mathrm{hrs}$ per day), $14 \mathrm{~L}$ (light for $14 \mathrm{hrs}$ per day) and $16 \mathrm{~L}$ (light for $16 \mathrm{hrs}$ per day) during mating periods, queens mated at $14 \mathrm{~L}$ (light for $14 \mathrm{hrs}$ per day) showed better results than at $12 \mathrm{~L}$ and $16 \mathrm{~L}$ for egglaying characteristics and colony development. An intensity of 1000 lux was more effective than an intensity of 100 ux or 2000 lux in mating $B$. ignitus queens. The most favorable mating and care temperatures for $B$. ignitus queens before mating were $22-25^{\circ} \mathrm{C}$ and $19^{\circ} \mathrm{C}$, respectively. The period needed to mate a $B$. ignitus queen was 3 days, and the number of queens suitable per mating cage of $55 \times 45 \times 65 \mathrm{~cm}$ was 30 (Yoon et al., 2007). Ono (1997) reported that the mating efficiency of $B$. ignitus, B. hypocrita hypocrita and $B$. h. sapporoensis was increased by controlling the light-dark condition (2L-22D) and temperature $\left(22^{\circ} \mathrm{C}\right.$ at $\mathrm{L}, 17^{\circ} \mathrm{C}$ at $\left.\mathrm{D}\right)$ using a low-temperature incubator. Like most Western bumblebees, B. terrestris queens become receptive at 6 days of age, whereas most males begin responding to queens at about 10 days of age (Duchateau, 1985; Tasei et al., 1998; Ptacek, 2000). Mating lasts at least half an hour in B. terrestris and a number of other species (Röseler, 1973; Duvoisin et al., 1999; Brown et al., 2002). B. terrestris was mated in a copulation room maintained at $20^{\circ} \mathrm{C}$ and $70 \%$ R.H. with a light intensity of 2000 lux from a halogen lamp (Djegham et al., 1994). Generally, the European bumblebee, B. terrestris, was mated during a 7 day period (Djegham et al., 1994; Tasei et al., 1998).

\section{Methods for breaking diapauses}

The effect of $\mathrm{CO}_{2}$-treatment on interrupting diapause in $B$. ignitus was examined for its potential to provide a means for year-round rearing of the bumblebee. When young mated queens were exposed to $65 \%$ or $99 \% \mathrm{CO}_{2}$ for 30 min daily for two consecutive days, the oviposition rate increased to $75 \%$ and $77 \%$, respectively. At the same time, the days needed before first oviposition shortened to 17-18 days in $\mathrm{CO}_{2}$-treated queens, compared to 30 days in $\mathrm{CO}_{2}$-untreated queens. $\mathrm{CO}_{2}$-treatment on the second day after mating was favorable for oviposition and colony development. $\mathrm{CO}_{2}$-treatment showed a positive effect on oviposition and colony development, but $\mathrm{CO}_{2}$-treated queens still produced fewer progeny than over-wintered queens (Yoon et al., 2003). Röseler (1985) reported that $\mathrm{CO}_{2}$ narcosis time is one day after mating and that $\mathrm{CO}_{2}-$ treated queens became very active and flew in the gauze cage. According to Tasei (1994), the timing of $\mathrm{CO}_{2}$ narcosis after mating did not affect the delay of egg-laying within the range of 5-30 days. For B. hypocrita and $B$. ignitus, the timing of $\mathrm{CO}_{2}$ narcosis is 2-4 days after mating (Ono, 1997). In terms of the physiological effects of $\mathrm{CO}_{2}$ narcosis, Röseler and Röseler (1984) demonstrated that narcotizing prediapausing queens with carbon dioxide (a 30 min narcosis repeated twice) inhibited the formation of fat reserves, increased the amount of juvenile hormone in vitro, and induced oogenesis.

Artificial hibernation is essential for year-round rearing of $B$. ignitus, which undergoes one generation per year. It is known that maintaining the queens at a low temperature for two or three months is an effective way to terminate their diapause and develop the colony. Temperature, time and surroundings for the queens during artificial hibernation were investigated. Among the tested temperatures $\left(-2.5^{\circ} \mathrm{C}, 0^{\circ} \mathrm{C}, 2.5^{\circ} \mathrm{C}\right.$, and $\left.5^{\circ} \mathrm{C}\right)$, the optimum temperature was $2.5^{\circ} \mathrm{C}$, at which the survival rate after chilling of the queens was high and colony development thereafter was 


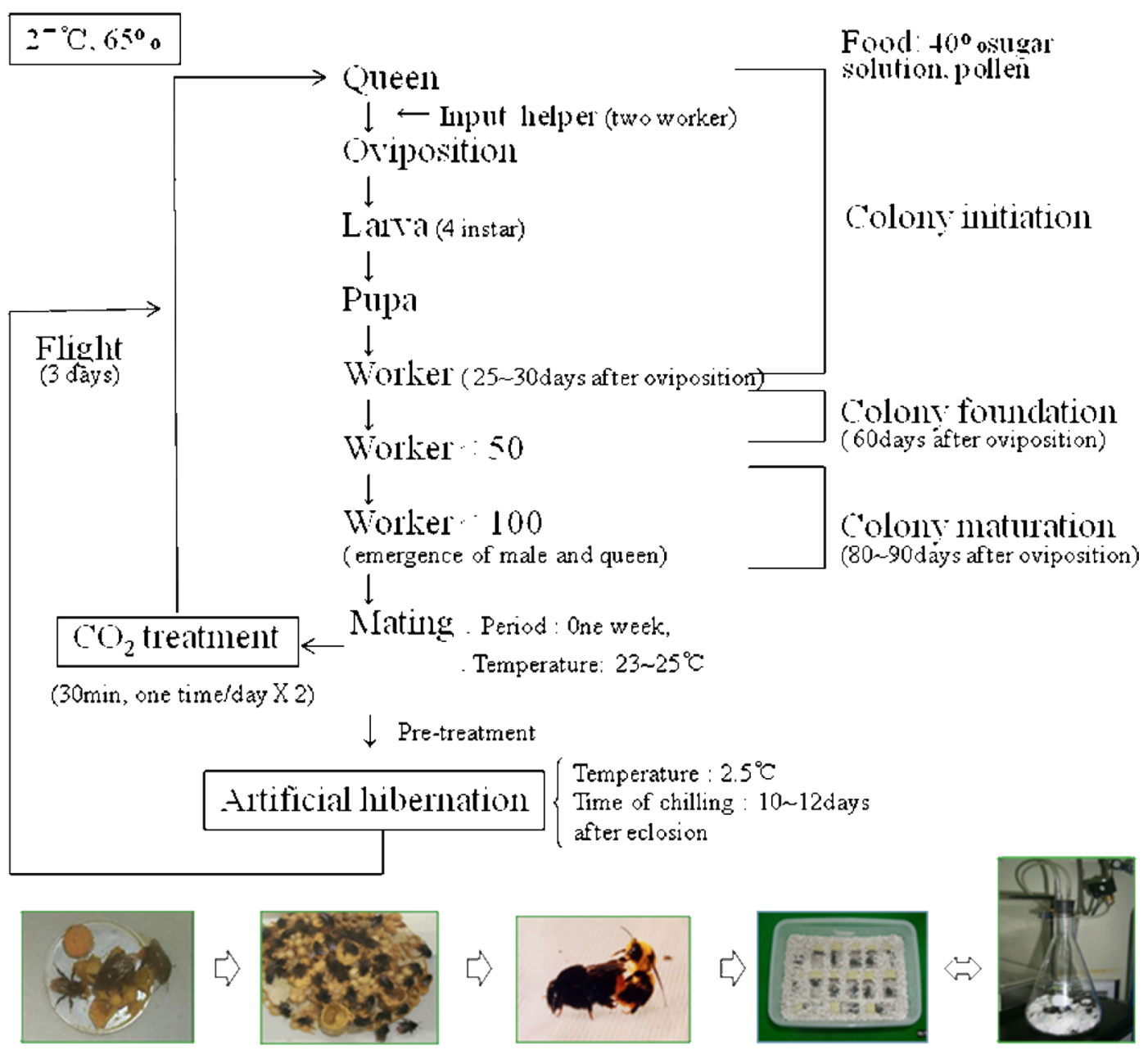

Fig. 5. Year-round rearing system for the Korean native bumblebee, B. ignitus.

enhanced. The proper time to initiate chilling of the queen was 10 to 14 days after adult eclosion, and the survival of the queens after chilling was good. For the surroundings of the queen during artificial hibernation, we proposed the method of preserving them in a bottle filled with perlite and keeping it at approximately 80\% R.H (Yoon, 2003). In year-round rearing of bumblebees, one of the key stages is diapause break. To break diapause, several authors have tried to induce hibernation of bumblebee queens under controlled conditions, despite the long ovarian diapause in bumblebees. Hoem (1972) maintained hibernating $B$. terrestris queens in mounds of soil in unheated greenhouses or in plastic containers with perlite as bedding; bees were then placed into a refrigerator at 4 $-5^{\circ} \mathrm{C}$ for 8-9 months. Asada (2004) reported that chilling in a refrigerator at $5^{\circ} \mathrm{C}$ for 4 months was effective at inducing nest initiation by $B$. h. hypocrita queens. Beekman et al. (1998) showed that weight prior to entering diapause has an important effect on the diapause survival of bumblebee queens: queens with a wet weight below $0.6 \mathrm{~g}$ were unable to survive diapause, irrespective of diapause length.

We investigated whether or not flight has any effect on oviposition and colony development of the artificially hibernated $B$. terrestris queen and $\mathrm{CO}_{2}$-treated queen. Flight periods were defined as 0 days (control), 1 day, 3 days or 6 days. The weights of queens after flight were $1.5-8.9 \%$ lower than those before flight depending on the flight periods. Oviposition and colony development of artificially hibernated and $\mathrm{CO}_{2}$-treated $\mathrm{B}$. terrestris queens were affected by the flight. Among the flight periods tested, in particular, the queens that flew for 3 days had better colony development, rate of colony foundation, rate of progeny-queen production, and the number of workers and queens produced. However, for queens hibernated artificially and $\mathrm{CO}_{2}$-treated, the longer the flight periods (i.e., 6 days of flight), the worse the oviposition and colony development were (Yoon et al., 2004b). Social bees 
and wasps are also able to use the heat produced in their flight muscles for brood incubation and for active regulation of nest temperatures (Heinrich, 1974; Seeley and Heinrich, 1981; Schltze-Motel, 1991). Beekmen et al. (1996) reported that after diapause was terminated, B. terrestris queens were kept in the mating cage for one week, after which they were moved to small boxes. As the above results show, we established a year-round rearing system for the bumblebee B. ignitus (Fig. 5).

\section{Conclusion}

Bees are vital to the well-being of humans. Products from pollinated plants, including fruits, vegetables, and seed crops, feed not only people but also livestock. Commercial bees, including bumblebees, honeybees and several nonsocial bees, provide farmers the opportunity to decrease their pollination labor costs and promise a good crop yield, both in quantity and in quality. However, managing bees can be problematic due to the dynamics of rearing organisms in close proximity and in controlled situations. We are pursuing a better understanding of the domestic management of bees because disease epidemics can devastate or impair the production of commercial pollinators. The extent of our reliance on these species for pollination services is risky. Therefore, we must also concern ourselves with research on the conservation and enhancement of populations of wild pollinators to protect the stands of native flora located in the vicinity of crops that are pollinated by commercial bees.

\section{Acknowledgement}

This study was carried out with the support of "Research Program for Agricultural Science \& Technology Development (PJ006801032011), National Academy of Agricultural Science, Rural Development Administration, Republic of Korea.

\section{References}

Asada S, Ono M (2000) Difference in colony development of two Japanese bumblebee, Bombus hypocrita and B. ignitus (Hymenoptera; Apidae). Appl Entomol Zool 35, 597-603.

Asada S (2004) Studies on year-round rearing of Japanese native bumblebees (Bombus spp.) for buzz-foraging crop pollination. Bull Kanagawa Pref Agric Res Insti 144, 3-18.

Aupinel P, Gènissel A, Gomond S, Tasei JN, Poncet J (2001) Collection of spring pollens by Bombus terrestris queens, assessment of attractiveness and nutritive value of pollen diets. Acta Hortic 561, 101-105.

Beekman M, van Stratum P, Veerman A (1996) Diapause in bumblebee Bombus terrestris. Proc Exp Appl NEV Amsterdam 7, 71-75.

Beekman M, van Stratum P, Lingeman R (1998) Diapause survival and post-diapause performance in bumblebee queens (Bombus terrestris). Entomol Exp Appl 89, 207-214.

Beekman M, van Stratum P, Lingeman R (2000) Artificial rearing of bumble bees (Bombus terrestris) selects against heavy gueens. J Apicult Res 39, 61-65.

Brown MJF, Baer B, Schmid-Hempel R, Schmid-Hempel P (2002) Dynamics of multiple-mating in the bumblebee bee Bombus hypnorum. Insect Soc 49, 315-319.

Carreck N, Williams I (1998) The economic value of bees in the UK. Bee World 79, 115-123.

Chambers S (1990) Feeding pollen to honeybees for colony development. Bee World 71, 35-37.

Corbet SA, Chapman IH, Osborne JL (1991) Bees and the pollination of crops and wild flowers in the European community. Bee World 72, 47-59.

Dafni A (1998) The threat of Bombus terrestris spread. Bee World 79, 113-114.

Dafni A, Shimida A (1996) The possible ecological implications of the invasion of Bombus terrestris (L.) (Apidae) at Mt Carmel, Israel. in The conservation of bees. Matheson AC (ed), pp. 183-200, The Linnean Society of London and The International Bee Research Association, London, UK.

Dag A, Kammer Y (2001) Comparison between the effectiveness of honeybee (Apis millifera) and bumblebee (Bombus terrestris) as pollinators of greenhouse sweet pepper (Capsicum annuum). Am Bee J 141, 447-448.

Danilevskii AS (1965) Photoperiodism and seasonal development of insects. Olyve and Boyd, Edinburgh and London.

Day S, Beyer R, Mercer A, Ogden S (1990) The nutrient composition of honeybee-collected pollen in Otage, New Zealand. J Apic Res 29, 138-146.

Djegham Y, Verhaeghe JC, Rasmout P (1994) Coupulation of Bombus terrestris L. (Hymenoptera: Apidae) in captivity. J Apic Res 33, 15-20.

Duchâteau MJ (1985) Analysis of some methods for rearing bumblebee colonies. Apidologie 16, 225-227.

Duchâteau MJ, Velthuis HW (1988) Development and reproductive strategies in Bombus terrestiris colonies. Behav 107, 186-207.

Duchâteau MJ, Velthuis HHW (1989) Ovarian development and egg laying in workers of Bombus terrestris. Entomol Exp Appl 51, 199-213.

Duchâteau MJ (1991) Regulation of colony development in bumblebees, Bombus terrestris. J Entomol 7, 141-151.

Duvoisin N, Baer B, Schmid-Hempel P (1999) Sperm transfer and male competition in a bumblebee. Anim Behav 58, 743749.

Eijnde J van den, Ruijter A de, Steen J van der (1991) Method for rearing Bombus terrestris continuously and the produc- 
tion of bumblebee colonies for pollination purposes. Acta Hortic 288, 154-158.

Free JB (1993) Insect pollination of crops. 2nd ed., Academic Press, London.

Gallai N, Salles JM, Settle J, Vaissiere BE (2009) Economic valuation of the vulnerability of world agriculture confronted with pollinator decline. Ecol Econ 68, 810-821.

Génissel A, Aupinel P, Bressac C, Tasei JN, Chevrier C (2002) Influence of pollen origin on performance of Bombus terrestris micro-colonies. Entomol Exp Appl 104, 329-336.,

Greenleaf S, Kremen C (2006) Wild bee species increase tomato production but respond differently to surrounding land use in Northern California. Biol Conserv 133, 81-87.

Gretenkord C, Drescher W (1997) Successful colony foundation and development of experimentally hibernated Bombus terrestris queens depending on different starting methods. Acta Hortic 437, 271-276.

Griffin RP, Macfarlane RP and van den Ende HJ (1991) Rearing and domestication of long tongued bumblebee in New Zealand. Acta Hortic 288, 149-153.

Groot AP de (1953) Protein and amino acids requirements of the honeybee (Apis mellifera L). Physiol Comp Oecol 3, 197-285.

Hannan MA, Maeta Y and Hoshikawa K (1998) Feeding behavior and food consumption in Bombus ignitus under artificial condition (Hymenoptera: Apidae). Entomol Sci 1: 27-32.

Heemert C van, Ruuter A de, Eundem J van Den and J van der Steen (1990) Year-round production of bumblebee colonies for crop pollination. Bee World 71, 54-56.

Heinrich B (1974) Thermoregulation in bumblebee. I. Brood incubation by Bombus vosnesenskii queens. J Comp Physiol Zool 88, 129-140.

Hoem SN (1972) Weight and life length of hibernation bumblebee queens (Hymenoptera: Bombidae) under controlled conditions. Ent Scand 3, 313-320.

James RR, Pitts-Singer TL (2008) Bee pollination in agricultural ecosystems. Oxford University Press, Inc. New York.

Klein AM, Vassiere B, Cane JH, Steffan-Dewenter L, Cunningham SA, Kremen C (2007) Importance of crop pollinators in changing landscapes for world crops. Proc Royal Soc London B 274, 303-313.

Michener CD (2000) The bees of the world. Baltimore: Johns Hopkins University Press.

Mitsuhata M, Ono M (1996) Hybridization between Japanese and European bumblebees (Bombus spp.). Proceedings of the 7th International Pollination Symposium held in Lethbridge, Alberta, Canada.

Mitsuhata M (2000) Pollination of crops with bumblebee colonies in Japan. Honeybee Sci 21, 17-25.

Morandin LA, Winston ML (2005) Wild bee abundance and seed production in conventional, organic, and genetically modified canola. Ecol Appl 15, 871-881.

Ono M, Mitsuhata M, Sasaki M (1994a) Use of introduced Bombus terrestris worker helpers for rapid development of
Japanese B. hypocrita colonies (Hymenoptera; Apidae). Appl Entomol Zool 29, 413-419.

Ono M, Suzuki M, Sasaki M, Matsuka M (1994b) Food processing strategy of bumblebees (Hymenoptera: Apidae); in Les Insectes Soxiaux. Lenoir A, Amold G, Lepage M (eds), pp. 487. Publ. Univ. Paris Nord.

Ono M, Wada T (1996) The world of the bumblebee. Japanese Association of Plant Protion, p. 132, Tokyo, Japan.

Ono M (1997) Ecological implication of introduced Bombus terrestris, and significance of domestication of Japanese native bumblebees (Bombus spp.). Proc. Int'l. Workshop on biological invasions of ecosystem by pests and beneficial organisms NIAES, MAFF, Tsukuba, Japan. pp. 242-252.

Ono M (1999) Breeding of bumblebees-utilization of biological resources. Insectarium 36, 328-332.

Plowright RC, Jay SC (1966) Rearing bumblebee colonies in capacity. J Apicul Res 5, 155-165.

Plowright RC, Pendrel RA (1977) Larval growth in bumblebees (Hemenoptera-Apidae). Can Entomol 109, 967-973.

Ptacek V (1985) Testing three methods of rearing bumblebees Sb. Ved Prac VSUP Troubsko 9, 59-67.

Ptacek V (1991) Trials to rear bumblebees. Acta Hort 288, 144-148.

Ptacek V (2000) Obtaining and overwintering young bumblebee (Hymenoptera, Bombinae) quens; in Insect pollination in greenhouses. Sommeijer MJ, de Ruijter A (eds), pp. 55-57, Utrecht University \& Ambrosiushoeve, Utrecht, Hivarenbeek.

Regali A, Rasmont P (1995) Nouvelles méthods de test pour l'èvalution du régime alimentaire chex des colonies prphelines de Bombus terrestris (L) (Hymenoptera, Apidae). Apidologie 26, 273-281.

Ribeiro MF, Duchâteau MJ, Velthuis HHW (1996) Comparison of the effects of commercially available pollen on colony development and queen production in the bumblebee, Bombus terrestris. Apiologie 27, 133-144.

Röseler PF (1973) Die Anzahl der Spermien im Receptaculum seminis won Hummelköniginnen (Hym., Apidea, Bombinae). Apidologie 4, 267-274.

Röseler PF (1985) A technique for year-round rearing of Bombus terrestris (Apidae, Bombini) colonies in captivity. Apidologie 16, 165-170.

Röseler PF, Röseler I (1984) Effects of carbon dioxide and brain cauterization on corpora allata activity and oogenesia in bumblebees (Bombus hypnorum and Bombus terrestris). Zool Jb Physiol 88, 237-246.

Roulston TH, Cane JH (2000) Pollen nutritional content and digestibility for animals; in Pollen and pollination. Dafni A, Hesse M, Pacini E (eds), pp. 187-209, Springer-Verlag, Wien.

Seeley Y, Heinrich B (1981) Regulation of temperature in nest of social insects; in Insect Thermoregulation. de Heinrich B (ed), pp. 159-234, Wiley, New York.

Stanley RG, Linskens HF (1974) Pollen, Springer-Verlag, Berlin.

Tasei JN (1994) Effect of different narcosis procedures on 
initiating oviposition of prediapausing Bombus terrestris L. queens. Entomol Exp Appl 72, 273-279.

Tasei JN, Aupinel P (1994) Effect of photoperiodic regimes on the oviposition of artificially overwintered Bombus terrestris L. queens and the production of sexuals. J Apic Res 33, 27 33.

Schltze-Motel P (1991) Heat loss and thermoregulation in a nest of the bumblebee Bombus lapidaries (Hymenoptera, Apidae). Thermochim Acta 193, 57-66.

Semmens TD, Turner E, Buttermore R (1993) Bombus terrestris (L.) (Hymenoptera: Apidae) now established in Tasmania. J Aus Entomol Sci 32, 346.

Sumner DA, Boriss H (2006) Bee-economics and the leap in pollination fees. Agric Res Econ Update 9, 9-11.

Sutcliffe GH, Plowright RC (1988) The effects of food supply on adult size in the bumblebee Bombus terricola Kirby (Hymenoptera: Apidae). Can Entomol 120, 1051-1058.

Tasei JN, Moinard C, Himpens B, Guyonnaud S (1998) Relationship between age, mating and sperm production in captive Bombus terrestris. J Apic Res 37, 107-113.

Velthuis HHW, van Doorn V (2006) A century of advances in bumblebee domestication and the economic and environmental aspects of its commercialization for pollination. Apidologie 37, 421-451.

Washitani I (1998) Conservation-ecological issues of the recent invasion of Bombus terrestris into Japan. Jap J Ecol $48,73-78$.

Williams JH (1994) The dependence of crop production within the European Union on pollination by honey bees. Agric Zool Rev 6, 229-257.

Winfree R, Griswold T, Kremen C (2007) Effect of human disturbance on bee communities in a forested ecosystem. Conserv Biol 21, 213-223.

Yoon HJ, Mah YI, Lee MY, Park IG, Bilinski M (1999) Ecological characteristics of Bombus ignitus Smith in Korea. Korean J Appl Entomol 38, 101-107.
Yoon HJ, Kim SE, Kim YS (2002) Temperature and humidity favorable for colony development of the indoor-reared bumblebee, Bombus ignitus. Appl Entomol Zool 37, 419-423.

Yoon HJ, Kim SE (2002) Facilitating effect of helpers on oviposition and colony development of bumblebee queen, Bombus ignitus. Korean J Appl Entomol 41, 239-245.

Yoon HJ (2003) The method of artificial hibernation of the bumblebee, Bombus ignitus. RDA Res Ext 44, 17-19.

Yoon HJ, Kim SE (2003) Effect of photoperiodic regimes on oviposition and colony development of bumblebee, Bombus ignitus. Int J Indust Entomol 7, 151-154.

Yoon HJ, Kim SE, Lee SB, Park IG (2003) Effect of $\mathrm{CO}_{2}$-treatment on oviposition and colony development of the bumblebee, Bombus ignitus. Korean J Appl Entomol 42, 139-144.

Yoon HJ, Kim SE, Kim YB, Lee SB (2004a) Colony developmental characteristics of the bumblebee queen, Bombus ignitus by the first oviposition day. Int J Indust Entomol 8, 139143.

Yoon HJ, Lee SB, Kim SE, Seol KY (2004b) The flight of the bumblebee queen, Bombus terrestris after diapauses termination affects to oviposition and colony development. Int $\mathbf{J}$ Indust Entomol 9, 241-247.

Yoon HJ, Kim SE, Lee KY, Lee SB, Park IG (2005a) Oviposition and colony development of the bumblebee, Bombus ignites and B. terrestris depending on different pollen. Int $\mathbf{J}$ Indust Entomol 11, 99-105.

Yoon HJ, Kim SE, Lee SB, Seol KY (2005b) The effect of antiseptic and sugar solution on colony development of the bumblebee queen, Bombus ignites and B. terrestris. Int $\mathbf{J}$ Indust Entomol 11, 43-48.

Yoon HJ, Kim SE, Lee KY, Lee SB, Park IG (2007) Mating conditions favorable for improving mating rate of the bumblebee, Bombus ignitus. Int J Indust Entomol 15, 107-114.

Yoon HJ, Kim SY, Lee KY, Lee SB, Park IG, Kim I (2009) Interspecific hybridization of the bumblebee, Bombus ignitus and B. terrestris. Int J Indust Entomol 18, 41-48. 